\title{
Deteksi Kematangan Buah Tomat Berdasarkan Warna Buah dengan Menggunakan Metode $\mathrm{YCbCr}$
}

\author{
Muhammad Syahputra Nasution ${ }^{1}$, Nurul Fadillah ${ }^{2}$ \\ ${ }^{I}$ Mahasiswa Program Studi Teknik Informatika, Fakultas Teknik, Universitas Samudra, Indonesia \\ ${ }^{2}$ Dosen Progam Studi Teknik Informatika, Fakultas Teknik, Universitas Samudra, Indonesia
}

KEYWORDS

RGB, YCbCr, Tomato Fruit

\section{CORRESPONDENCE}

\section{Phone:}

E-mail: msn17061997@gmail.com

\begin{abstract}
A B S T $\mathbf{T}$ R A C $\mathbf{C}$ T
Tomato fruit is one of the fruits that has a complex color to determine its maturity. Tomatoes have 3 colors to determine whether the tomatoes are ripe, half-cooked and raw, which is red when the tomatoes are ripe, yellow when the tomatoes are half cooked, and green when the tomatoes are raw. To determine the maturity of tomatoes is not only done conventionally (manually), but can also be done by computing (technology-based). One of the right methods to determine the maturity of tomatoes based on the color is computationally, using the $\mathrm{YCbCr}$ method. In this study we will see how the results of RGB conversion to $\mathrm{YCbCr}$ to determine the maturity of tomatoes. The results obtained in this study, namely when the original image (RGB) is converted to $\mathrm{YCbCr}$ images, then for the color of ripe tomatoes will be purple, for the color of half-ripe tomatoes will be colored magenta, and for the color of tomatoes that are still raw will be red.
\end{abstract}

Buah tomat merupakan salah satu buah yang memiliki warna yang komplek suntuk menentukankematangannya. Buahtomat memiliki 3 warna untuk menentukan apakah buat tomat tersebut sudah matang, setengah matang, dan mentah, yaitu warna merah ketika buah tomat sudah matang, warna kuning ketika buah tomat setengah matang, danwarna hijau ketika buah tomat mentah. Untuk menentukan kematangan buah tomat tersebut tidak hanya dilakukan secara konvensional (manual), tetapi bisa juga dapat dilakukan secara komputing (berbasis teknologi). Salah satu metode yang tepat untuk menentukan kematanganbuahtomat berdasarkan warnanya secara komputing, yaitu menggunakan metode $\mathrm{YCbCr}$. Pada penelitian ini akan dilihat bagaimana hasil konversi RGB ke YCbCr untuk menentukan kematangan pada buah tomat. Hasil yang didapat pada penelitian ini, yaitu ketika citra asli (RGB) di konversikan ke citraYCbCr maka untuk warna buah tomat yang sudahmatang akanberwarna ungu, untuk warna buah tomat setengah matang akan berwarna berwarna magenta, dan untuk warna buah tomat yang masih mentah akan berwarna merah.

\section{PENDAHULUAN}

Pada era teknologi sekarang ini, perkembangan teknologi semakin pesat. Salah satu pengembangan teknologi tersebut yaitu citra digital. Penggunaan citra digital pada kehidupan sehari-hari sangat bermanfaat dan banyak digunakan. Salah satu contohnya yaitu mendeteksi kematangan buah tomat berdasarkan warna buahnya. Buah tomat merupakan buah yang sangat kompleks dalam pewarnaannya untuk menentukan kematangannya, buah tomat memiliki 3 warna, yaitu warna merah ketika buah tomat matang, warna kuning ketika buah tomat setengah matang, dan warna hijau ketika buah tomat mentah.

Pada saat ini untuk menentukan kematangan buah tomat masih sering dilakukan secara konvensional (manual), dengan adanya citra digital maka untuk menentukan kematangan buah tomat berdasarkan warnanya bisa dilakukan secara komputing (berbasis teknologi) dengan metode YCbCr. Dengan metode $\mathrm{YCbCr}$, penentuan kematangan buah tomat berdasarkan warna tidak perlu lagi dilakukan secara konvensional (manual).

\section{LANDASAN PENELUSURAN}

\section{$\mathrm{YCbCr}$}

Ruang warna $\mathrm{YCbCr}$ atau yang disebut juga dengan ruang warna CCIR 601 (International Radio Consultative Committe). Model warna ini akan dikembangkan untuk mengantisipasi perkembangan informasi berbasiskan video, sehingga model ini banyak digunakan pada video digital. Secara umum dapat dikatakan bahwa model warna ini merupakan bagian dari ruang transmisi video dan televisi. Adapun model warna lain yang mirip dengan $\mathrm{YCbCr}$ adalah $\mathrm{YUV}$ dan YIQ, perbedaannya terletak bahwa $\mathrm{YCbCr}$ adalah system warna digital sedangkan yang lain adalah system warna analog. Model warna $\mathrm{YCbCr}$ akan memisahkan nilai RGB menjadi informasi luminance dan chrominance.

$\mathrm{YCbCr}$ adalah keluarga dari color space, salah satu cara penyandian informasi RGB yang sering dipakai pada bagian pewarnaan pada video dan fotografi digital. Dibagi menjadi 2 komponen, yaitu komponen luma (Y) dari luminasi dan komponen Kroma $(\mathrm{Cb}$ dan $\mathrm{Cr}$ ) yaitu perbedaan antara biru dan 
merah. Warna $\mathrm{YCbCr}$ ditentukan dari $\mathrm{CB}$ dan $\mathrm{CR}$, Y digunakan untuk menentukan besarnya luminasi sehingga setiap $\mathrm{Y}$ yang berbeda, pemetaan warna $\mathrm{Cb}$ dan $\mathrm{Cr}$ akan berbeda.

Model warna ini dikembangkan untuk mengantisipasi perkembangan informasi berbasis video, sehingga model ini banyak digunakan pada video digital. Secara umum dapat dikatakan bahwa model warna ini merupakan bagian dari ruang warna transmisi video dan televisi. Model warna $\mathrm{YCbCr}$ memisahkan nilai RGB menjadi informasi luminans dan krominans yang berguna untuk aplikasi kompresi citra

Rumus konversi RGB ke $\mathrm{YCbCr}$ :

$$
\begin{aligned}
& Y=0.299 R+0.587 G+0.114 B \\
& C b=B-Y \\
& C r=R-Y
\end{aligned}
$$

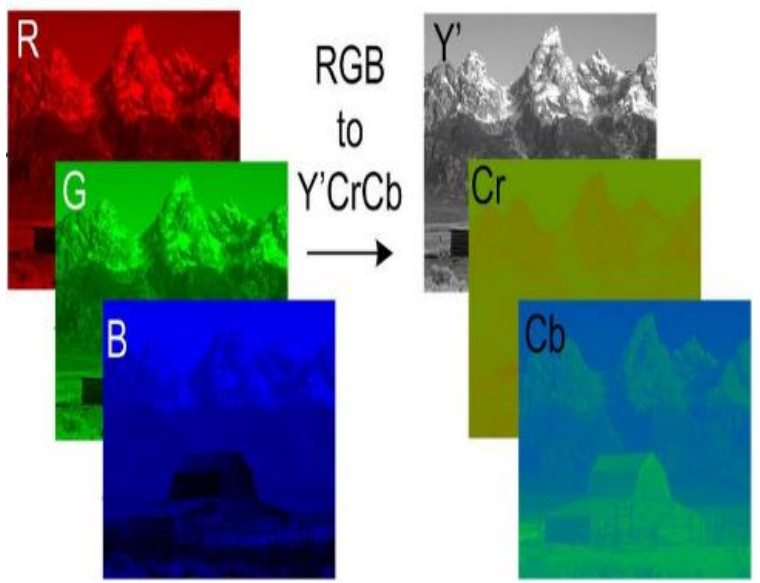

Gambar 1 (Konversi RGB ke YCbCr)

\section{METODE DIUSULKAN}

Metode penelitian ini secara garis besar terdapat beberapa proses yang akan dilakukan dalam penelitiaan ini. Pertama melakukan pengumpulan data-data gambar dari kumpulan buah tomat, buah tomat matang, buah tomat setengah matang dan buah tomat mentah. Kedua melakukan analisa dan perancangan sistem YCbCr dengan menggunakan bahasa pemrograman MATLAB. Kemudian dilakukan pengujian terhadap sistem $\mathrm{YCbCr}$ pada data - data gambar kumpulan buah tomat, buah tomat matang, buah tomat setengah matang dan buah tomat mentah dengan menggunakan bahasa pemrograman MATLAB. Ketika melakukan pengujian, maka input data gambar yang akan di konversi keYCbCr. Kemudian data gambar yang telah di input tersebut maka akan di proses dari citra asli (gambar inputan) menjadi cira $\mathrm{YCbCr}$. Setelah proses konversi dari citra asli (gambar inputan) menjadi $\mathrm{YCbCr}$ berhasil, maka akan menampilkan hasil citra YCbCr, maka akan terlihat perbedaan antara buah tomat yang sudah matang, buah tomat setengah matang, dan buah tomat mentah.

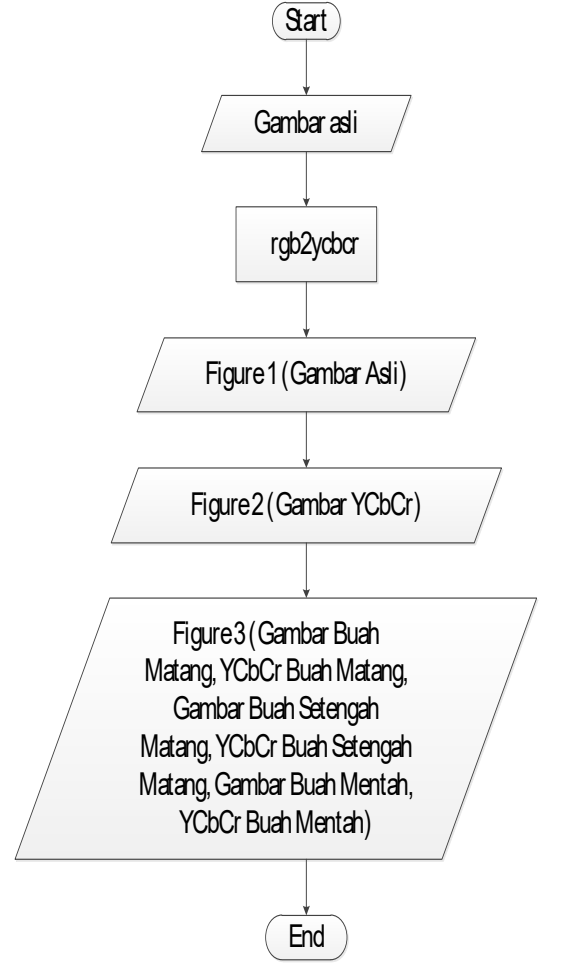

Gambar 2 (Perancangan Sistem Penelitian YCbCr)

\section{Input gambar asli}

Data citra (gambar) yang akan diinput yaitu terdapat 4 citra (gambar), yaitu gambar kumpulan buah tomat, gambar buah tomat yang matang, gambar buah tomat yang setengah matang, dengn berbuah tomat mentah.

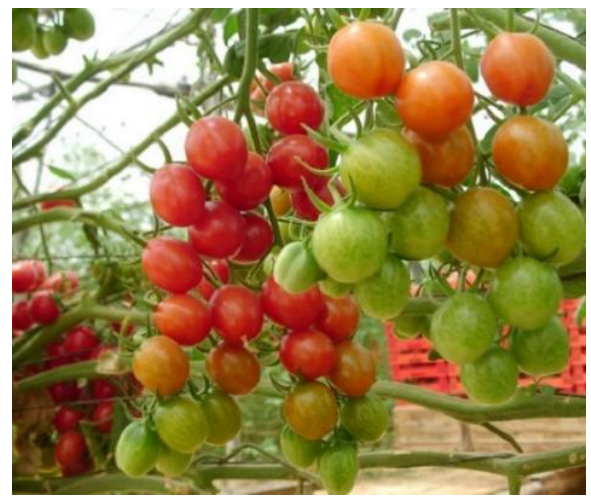

Gambar 3 (Gambar kumpulan buah tomat)

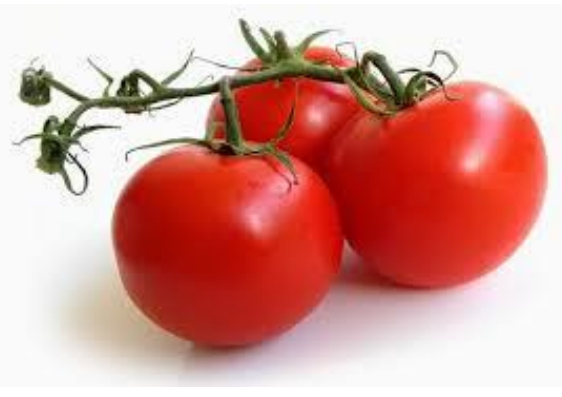

Gambar 4 (Gambar buah tomat matang) 


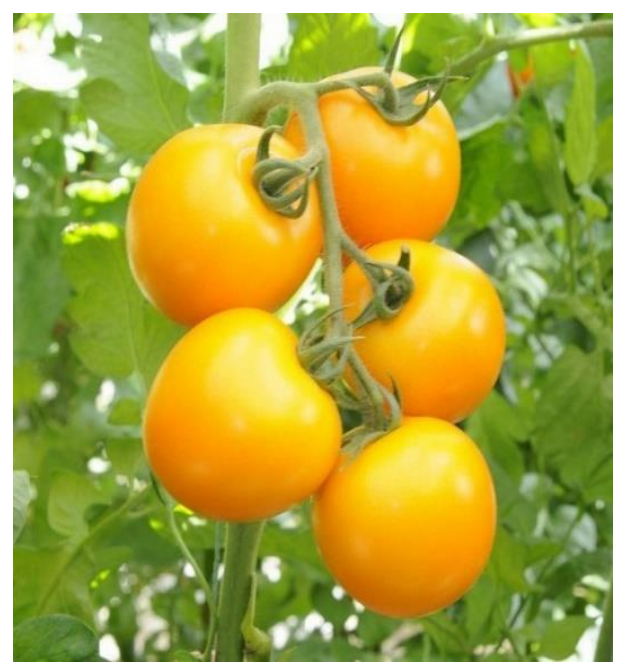

Gambar 5 (Gambar buah tomat setengah matang)

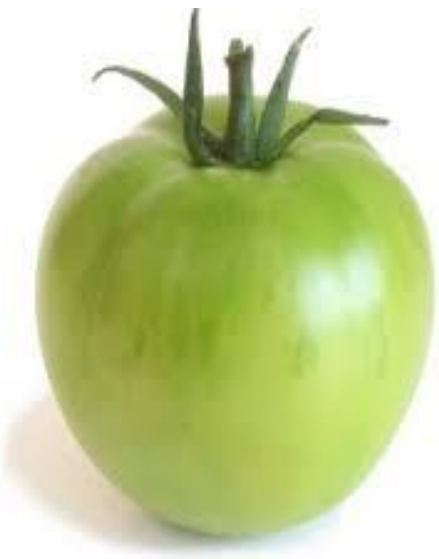

Gambar 6 (Gambar buah tomat mentah)

\section{Proses Perubahan Gambar Asli Menjadi YCbCr}

Pada proses perubahan citra RGB (asli) ke YCbCr dengan rumus dibawah ini :

$$
\begin{aligned}
& Y=0.299 R+0.587 G+0.114 B \\
& C b=B-Y \\
& C r=R-Y
\end{aligned}
$$

Ketika nilai $\mathrm{Y}, \mathrm{Cb}$, dan $\mathrm{Cr}$ sudah ditemukan, maka nilai-nilai tersebut disatukan agar terbentuk citraYCbCr
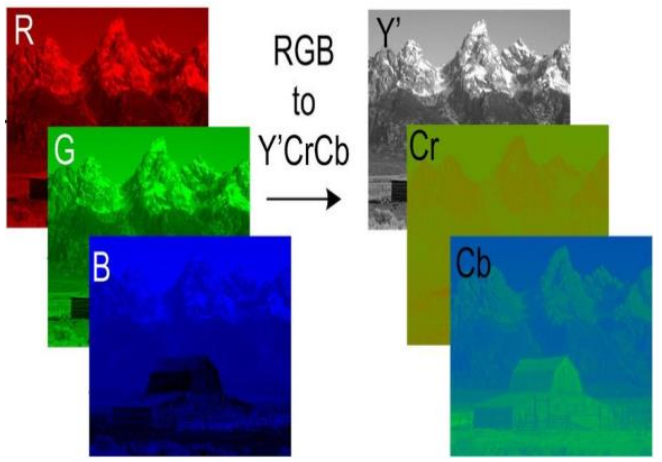

Gambar 7 (Gambarkonversi RGB ke YCbCr)

\section{Menampilkan Hasil $\mathrm{YCbCr}$}

Hasil yang akan ditampilkan pada hasil YCbCr ini yaitu, citra asli dari gabungan buah tomat pada figure1, citra $\mathrm{YCbCr}$ dari gabungan buah tomat pada figure2, dan Perbandingan citra asli dan citra YCbCr dari gambar buah tomat matang, buah tomat setengah matang, dan buah tomat mentah pada figure3.

\section{HASIL EKSPERIMEN}

Hasil yang akan ditampilkan pada hasil YCbCr ini yaitu, citra asli dari gabungan buah tomat pada figure1, citra $\mathrm{YCbCr}$ dari gabungan buah tomat pada figure2, dan Perbandingan citra asli dan citra $\mathrm{YCbCr}$ dari gambar buah tomat matang, buah tomat setengah matang, dan buah tomat mentah pada figure3.

$$
\text { A Figure } 1
$$

File Edit View Insert Tools Desktop Window Help

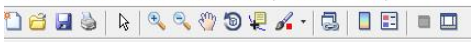

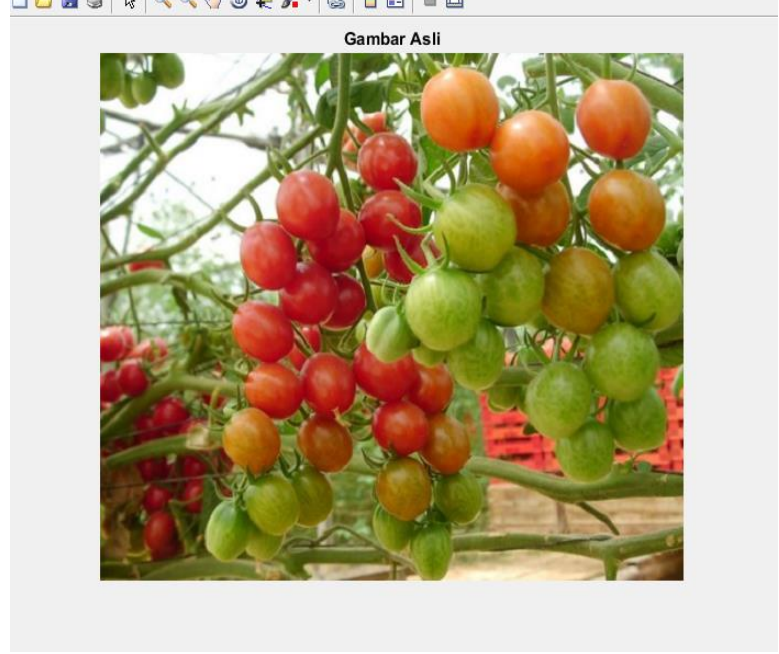

\section{Gambar 8 (Citra Asli)}

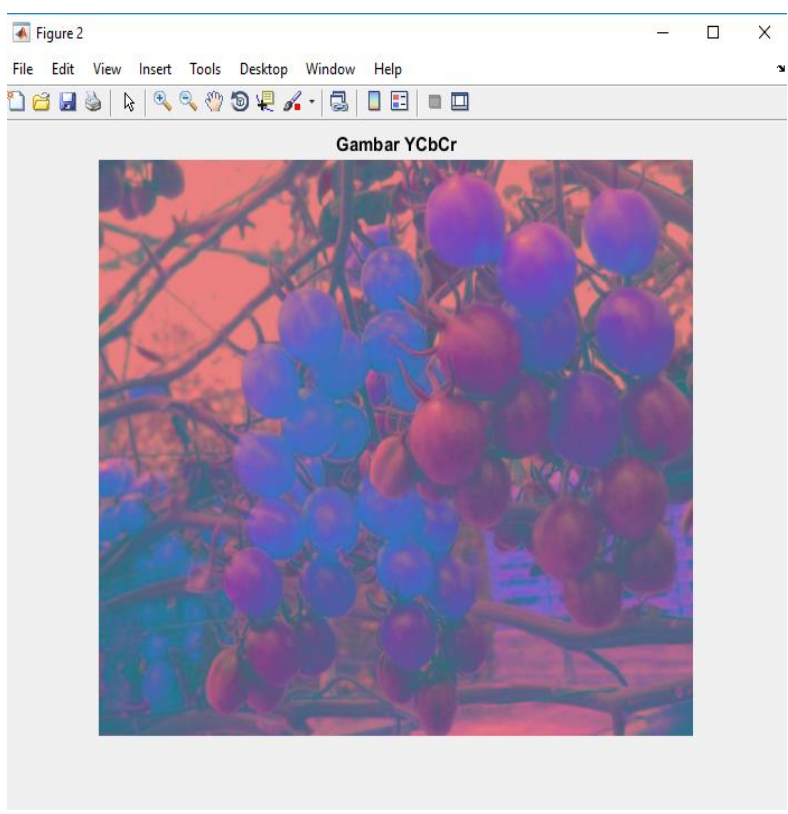

Gambar 9 (Citra YCbCr) 


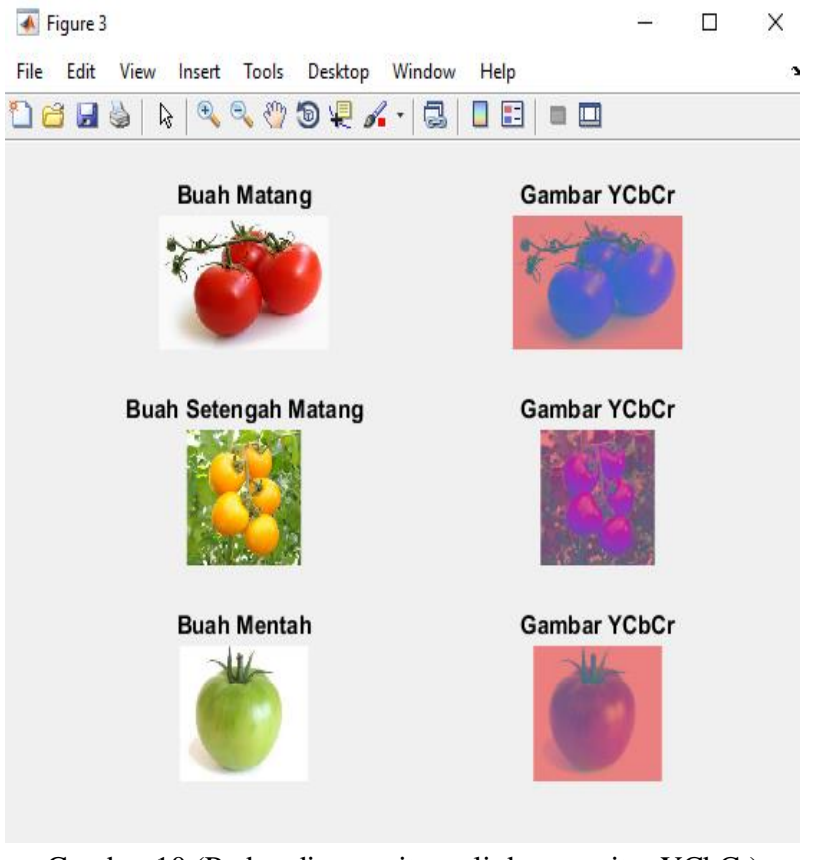

Gambar 10 (Perbandingan citra asli dengan citra $\mathrm{YCbCr}$ )

Setelah dilakukan pengujian terhadap buah tomat yang sudah matang, setengah matang, dan mentah maka didapatkan hasil bahwa buah tomat yang sudah matang setelah dikonversi dari RGB ke YCbCr maka akan berubah warna menjadi warna ungu, sedangkan untuk buah tomat yang setengah matang setelah dikonversi dari RGB ke YCbCr maka akan berubah warna menjadi warna magenta, dan untuk buah tomat yang mentah setelah dikonversi dari RGB ke YCbCr maka akan berubah warna menjadi warna merah.

\section{KESIMPULAN}

1. YCbCr adalah keluarga dari color space, salah satu cara penyandian informasi RGB yang sering dipakai pada bagian pewarnaan pada video dan fotografi digital.

2. YCbCr dibagi menjadi 2 komponen, yaitu komponen luma (Y) dari luminasi dan komponen Kroma ( $\mathrm{Cb}$ dan $\mathrm{Cr})$ yaitu perbedaan antara biru dan merah.

3. Konversi citra RGB (asli) ke citra $\mathrm{YCbCr}$ menggunakan rumus :

$$
\begin{aligned}
& Y=0.299 R+0.587 G+0.114 B \\
& C b=B-Y \\
& C r=R-Y
\end{aligned}
$$

4. Buah tomat yang matang setelah dikonversi menjadi citra YCbCr berwarna ungu.

5. Buah tomat yang setengah matang setelah dikonversi menjadi citra $\mathrm{YCbCr}$ berwarna magenta.

6. Buah tomat yang mentah setelah dikonversi menjadi citraYCbCr berwarna merah.

\section{REFERENSI}

[1] Erwin Rizki Ariyanto, "Implementasi Deteksi Citra Pornografi Berbasis Model Warna YCbCr dengan Metode Perbaikan C4.5 dan Shape Descriptor Untuk Filter Upload Foto di Media Sosial", Fakultas Ilmu Komputer, Teknik Informatika, Universitas Dian Nuswantoro Semarang, 2015.

[2] Nurul Hidayat, Muh. Arif Rahman, "Cara Cepat Untuk Mendeteksi Keberadaan WajahPada Citra Yang Mempunyai Background Kompleks Menggunakan Model Warna YCbCr Dan HSV", Fakultas Ilmu Komputer Universitas Brawijaya Malang, 2015.

[3] Rony Wijanarko, Nugroho Eko, "Deteksi Wajah Berbasis Segmentasi Warna Kulit Menggunakan Ruang Warna YCbCr\& Template Matching”, Fakultas Teknik Universitas Wahid Hasyim Semarang, 2011.

[4] Teguh Sutanto, "Kombinasi Penyaring Warna Kulit Kplisit Pada Bidang Warna RGB Dan YCbCr Untuk Meningkatkan Akurasi Sistem Pendeteksi Warna Kulit”, Program Studi Sistem Informasi, STIKOM Surabaya, 2010. 